\title{
Efficient conversion of solar energy to biomass and electricity
}

David Parlevliet ${ }^{1,3^{*}}$ and Navid Reza Moheimani ${ }^{2,3}$

\begin{abstract}
The Earth receives around $1000 \mathrm{~W} \cdot \mathrm{m}^{-2}$ of power from the Sun and only a fraction of this light energy is able to be converted to biomass (chemical energy) via the process of photosynthesis. Out of all photosynthetic organisms, microalgae, due to their fast growth rates and their ability to grow on non-arable land using saline water, have been identified as potential source of raw material for chemical energy production. Electrical energy can also be produced from this same solar resource via the use of photovoltaic modules. In this work we propose a novel method of combining both of these energy production processes to make full utilisation of the solar spectrum and increase the productivity of light-limited microalgae systems. These two methods of energy production would appear to compete for use of the same energy resource (sunlight) to produce either chemical or electrical energy. However, some groups of microalgae (i.e. Chlorophyta) only require the blue and red portions of the spectrum whereas photovoltaic devices can absorb strongly over the full range of visible light. This suggests that a combination of the two energy production systems would allow for a full utilization of the solar spectrum allowing both the production of chemical and electrical energy from the one facility making efficient use of available land and solar energy. In this work we propose to introduce a filter above the algae culture to modify the spectrum of light received by the algae and redirect parts of the spectrum to generate electricity. The electrical energy generated by this approach can then be directed to running ancillary systems or producing extra illumination for the growth of microalgae. We have modelled an approach whereby the productivity of light-limited microalgae systems can be improved by at least $4 \%$ through using an LED array to increase the total amount of illumination on the microalgae culture.
\end{abstract}

Keywords: Solar energy, Biofuel, Photovoltaics, Microalgae, Renewable

\section{Introduction}

\section{Light}

The irradiance from the sun varies widely with wavelength and has been well characterised [1]. The spectrum of the light outside the Earth's atmosphere (the extra-terrestrial spectrum) differs from the spectrum as measured from the Earth's surface (the terrestrial spectrum) due to absorption within the Earth's atmosphere. There are two standard terrestrial solar spectral irradiance distributions [2] used in the testing of photovoltaic modules. These provide a standard wavelength distribution of the solar irradiance which allows the efficiency and

\footnotetext{
* Correspondence: d.parlevliet@murdoch.edu.au

'School of Engineering and Information Technology, Physics and Energy, Murdoch 6150, Western Australia, Australia

${ }^{3}$ Murdoch University, Murdoch 6150, WA, Australia

Full list of author information is available at the end of the article
}

performance of different solar modules to be measured and compared.

There are two standard spectra defined in the standards [3]. The first of these is the direct normal spectrum, which is 'the direct component contributed to the total hemispherical (or 'global') radiation on a $37^{\circ}$-tilted surface' [3]. The latter is a reasonable average for photovoltaics panels tilted towards the equator, in the United States of America and regions of Australia and applies to Sun facing $37^{\circ}$-tilted surfaces [3]. The standard defined in ASTM G-173-03 takes into account average values for the atmospheric composition, aerosols, water vapour and ozone content [2].

A plot of the extra-terrestrial irradiance and the two spectra described in the ASTM G-173-03 standard is shown in Figure 1. The irradiance is dependent on the air mass, or path length of irradiation through the atmosphere. The spectra in ASTM G-173-0 use an air mass 


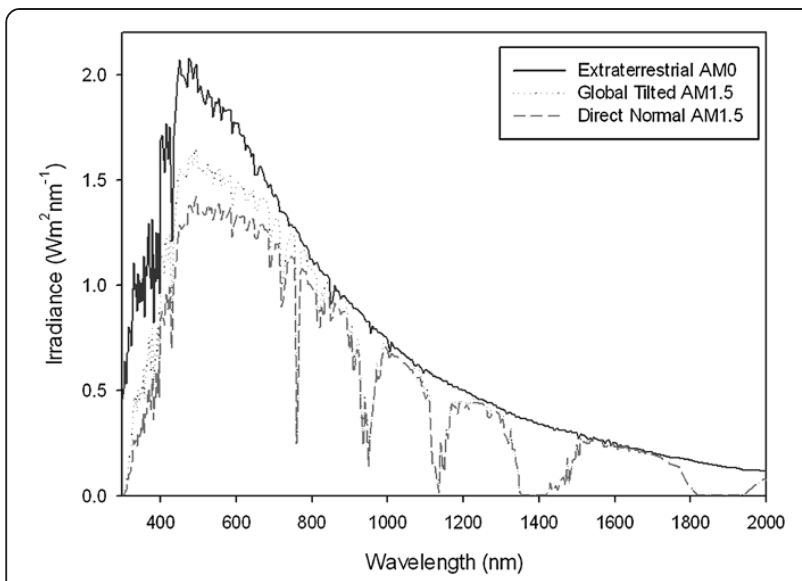

Figure 1 Solar spectrum as defined in ASTM G-173-03 [2].

of 1.5, which is a reasonable average for the mid-latitudes.

\section{Algae}

Algae are plant like organisms which contain Chlorophyll $a$, have oxygenic photosynthesis and have no specialised organelles [4]. Algae divide to both prokaryotic and eukaryotic organisms and range from uni-cellular microalgae (less than $1 \mu \mathrm{m}$ ) to multicellular macroalgae (as long as $60 \mathrm{~m}$ ) [4]. Algae can be found in any aquatic and moist habitats such as marine, freshwater and are common in soils, salt lakes and hot springs [4]. All photosynthetic algae require light to grow [5] and algal photosynthesis accounts for almost more than half of the total global primary productivity and form the basis of almost all of the aquatic food webs [6]. Microalgae have been identified as a potential source of bioenergy production $[7,8]$. There are many interacting factors such as light, dissolved $\mathrm{O}_{2}$, shear, $\mathrm{CO}_{2}, \mathrm{pH}$ and nutrients effecting and limiting the growth of microalgae [5]. However, light is the main limit to the growth of microalgae $[9,10]$. Photosynthetic pigments are responsible for absorbing light [11]. The algae are unique in the variation of these pigments in each phylum and in many classes [12]. The main reason for this diversity relates to each group ancestral lineage which has no close affinity between different groups of algae [13]. This diversity of pigments has also led to their recognition as taxonomic and phylogenetic markers [13]. Photosynthetic complexes are made up of Chlorophyll-like molecules including chlorophyll a, b, c, d and e, bacteriochlorophylls, pheophytin $\mathrm{a}$ and $\mathrm{b}$ and other kinds of pigment molecules such as carotenoid $\alpha$ and $\beta$, xantophylls [14]. Energy collected by the antenna complexes is transferred downward like a funnel to lower-lying, chlorophyllcontaining reaction centre pigment complexes [15]. It is well known that the number of reaction centres in the photosynthetic organisms is significantly smaller than the number of pigment molecules and most of the pigments function as antenna [16]. The earth receives $3.9 \times 10^{6}$ EJ of total solar energy each year [17]. The photosynthetic efficiency (PE) is the fraction of light energy converted to chemical energy through by photosynthetic organisms (i.e. algae, cynobacteria). The significance of PE is reliant on how light energy is defined. Actual sunlight where between photosynthetic active radiation (PAR) is only $45 \%$ and $48 \%$ of light [18], the theoretical maximum efficiency of solar energy conversion is between $11 \%$ and $12 \%\left(110 \mathrm{~W} \cdot \mathrm{m}^{-2}\right.$ to $\left.120 \mathrm{~W} \cdot \mathrm{m}^{-2}\right)$. It is to be noted that, to date, the average PE is between $2 \%$ and $5 \%$ [19]. The main reason for such a difference is that a) not all light can be captured by the pigments, b) only a portion of PAR can be converted and c) light and dark respiration can reduce the overall efficiency. It is to be noted that the excess light will be discarded (i.e. as heat or fluorescence) to avoid damaging the photosynthetic apparatus.

The main spectral absorption peaks for Chlorophylls a, b, and c [20] and several pigments present in various microalgae are shown in Figure 2. As can be seen the absorption peaks are predominantly in the blue and red portion of the spectrum with a significant portion of the spectrum in the green range being underutilised. This portion of spectrum could be used for another purpose without impacting on the growth of the microalgae [21].

\section{Photovoltaics}

The use of photovoltaics, or solar cells, has been described as the 'art of converting sunlight directly into electricity'. These solid state devices take incident illumination and produce a supply of electrons which can be used by an external circuit [22]. Photovoltaic devices are produced from a range of different materials. Of these, silicon is most commonly used as a semiconductor material for producing solid state solar cells. However, there is increasing interest in other technologies, many of which have been commercialised and are in production.

The first solar cell was produced from crystalline silicon and had a conversion efficiency of 6\% [23]. Through significant research and improvement, modern state of the art solar cells produced from crystalline silicon have been produced with conversion efficiencies of up to $25 \%$ and $22 \%$ in small laboratory and full modules, respectively $[24,25]$. In the marketplace there are several types of solar cell technologies available including crystalline, micro-crystalline and amorphous silicon. Due to their higher efficiencies and the economies of scale, the world market is dominated by crystalline silicon solar cells which held over $93.5 \%$ in 2005 [26]. 


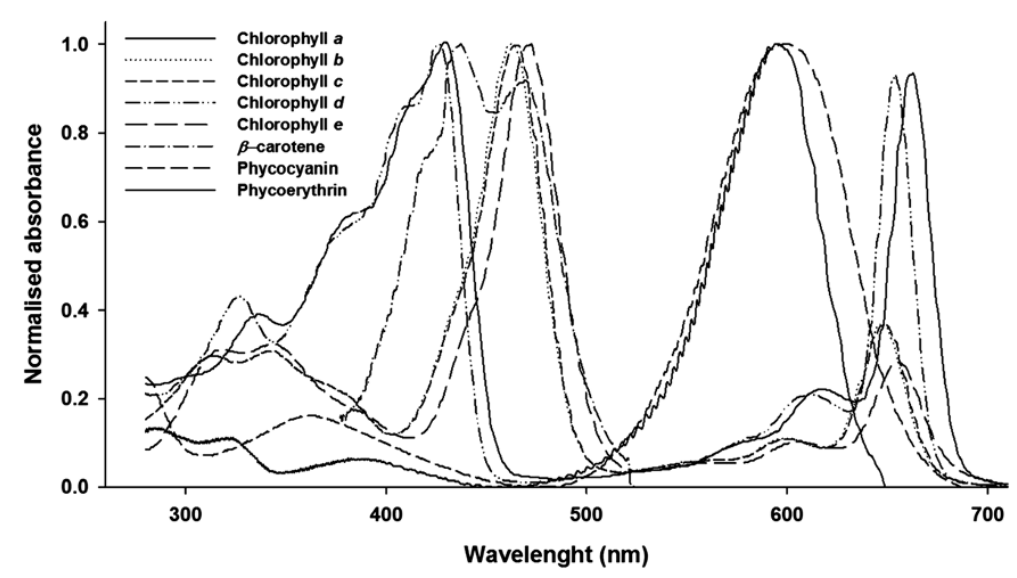

Figure 2 Normalized absorbance spectra of some photosynthetic pigments [20].

\section{Light emitting diodes}

Light emitting diodes (LEDs) are highly efficient solid state devices that can convert electrical current into light. The internal quantum efficiency of high quality LEDs can exceed 99\%, however there are difficulties in extracting the light from the LED which leads to low external quantum efficiencies (EQE) in the order of a few per cent [6].

There are a range of different technologies and materials used to produce LEDs and a large amount of research going into increasing the external quantum efficiency of these LEDs. These include blue emitting InGaN-GaN LED's with a EQE of 40\% [17], thin film GaAs LEDs with a 30\% EQE, [6] and organic LEDs with an EQE of 30\% [27]. In some cases careful texturing can improve the light extraction efficiency which yields LEDs with an EQE greater than $50 \%$ and in some cases up to $60.9 \%$ [28].

These LEDs with high external quantum efficiencies $(60.9 \%$ [28]) for particular wavelengths of light would be useful for adding additional targeted illumination to microalgae ponds.

In this work we propose introducing a filter above the algae pond to allocate the incident illumination to different purposes. The spectrum the filter transmits is allowed to be incident upon the algae pond, while the remainder is provided to a solar cell for electricity production. The nature of this blackbox filter and how the light is split between these two purposes is not a subject of this current work. We will assume that the filter can selectively transmit or redirect the different parts of the spectrum to different purposes with minimal energy loss. However, there are several candidate options, including a specifically tailored semitransparent thin film PV, luminescent solar concentrators, or other advanced energy harvesting flat glass panel that match the spectrum not used by the microalgae. One excellent candidate technology system can transmit arbitrary visible light wavebands, capture the infrared part of the spectrum, concentrate it on the edge of a glass panel and convert this to electricity [29].

In this work we have allocated the solar spectrum to different purposes using readily available lighting filters as model for the blackbox filter. The ideal spectrum to allocate to different uses will be dependent on the type of algae, response of growth rate and yield to different spectra and which parts of the spectrum are necessary for viable growth.

The models described in this work are designed to determine the portion of light that can be converted into electricity if different portions of the spectrum are redirected to the algae pond. This energy could be used to run ancillary systems in an algae pond or could be used to increase the illumination upon the pond using specific spectra generated by highly efficient LED lighting. These models also describe the potential improvement in yield if light is the limiting factor.

\section{Theory/Calculation}

We can model the concept of transmitting a portion of the solar spectrum to a microalgae pond and converting the remainder of the light into electricity via a conventional solar panel. This allows us to determine the viability of a cultivation system based on this concept in terms of generating electivity or increasing the portion of specifically targeted PAR available for cultivation. For this model we are not concerned with how the light will be collected by a solar panel but are investigating the allocation of the solar spectrum to different purposes. To this end we will use typical commercially obtainable filters as a model for the blackbox filter which divides the spectrum for different purposes. What the filter transmits will be allocated to the algae, what the filter does not transmit will be allocated to the solar cell. The ideal spectrum to allocate to different uses will be 
dependent on the type of algae, response of growth rate and yield to different spectra and which parts of the spectrum are necessary for viable growth and will be tailored in future experimental work.

The filters used in this study are LEE 026 Bright Red, LEE 363 Medium Blue and LEE 128 Bright Pink filters. The transmission of each of these was measured using ultraviolet and visible spectroscopy and is shown below in Figure 3.

For photovoltaic devices, the absorption of light is determined by the band-gap. This needs to be close to the peak of the energy range of the AM1.5 spectrum (1 eV to $3 \mathrm{eV}$ ) and not all semiconductors are suitable for use as solar cells, the most suitable band-gap for which is about 1 to $1.6 \mathrm{eV}$ [22]. Although photovoltaic devices would work with a higher efficiency if they only had to absorb monochromatic light [30], normally photovoltaic devices are designed to absorb as much of the solar spectrum as possible. The response to different components of the solar spectrum can be measured using the spectral response technique.

The spectral response of a solar cell is usually defined as the output current under short-circuit conditions per unit power of incident monochromatic light as a function of wavelength [31] and is a measure of the proportion of charge carriers generated by the incident photons.

There are several different technologies used in photovoltaic devices, including but not limited to: crystalline silicon [24,25], amorphous silicon [32,33] and microcrystalline silicon $[34,35]$. The external quantum efficiency curves of current state of the art single crystal silicon solar cells with an efficiency of 24\% [36] and a highly efficient single junction amorphous silicon device with a stable efficiency of 9.47\% [33] are shown in Figure 4.

From the reported spectral response graphs and parameters for crystalline silicon [25] and amorphous

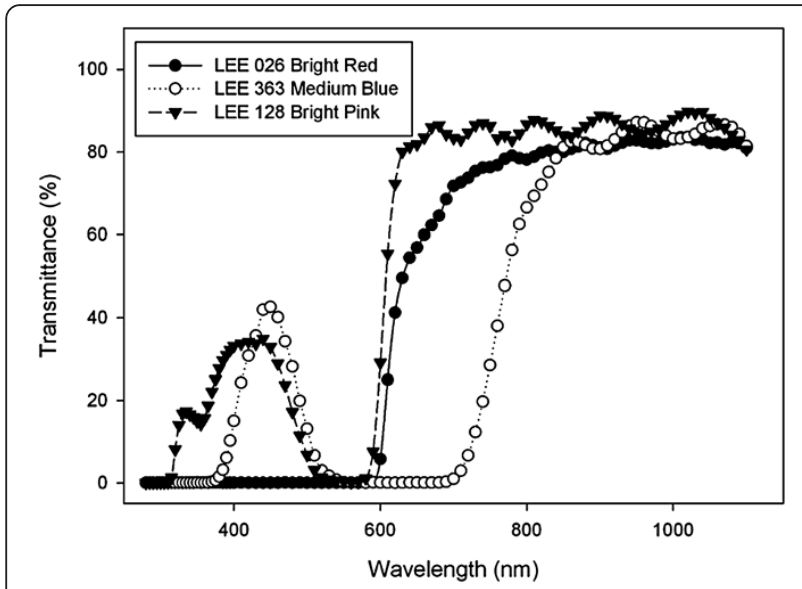

Figure 3 Transmittance of filters as measured with ultraviolet and visible spectroscopy.

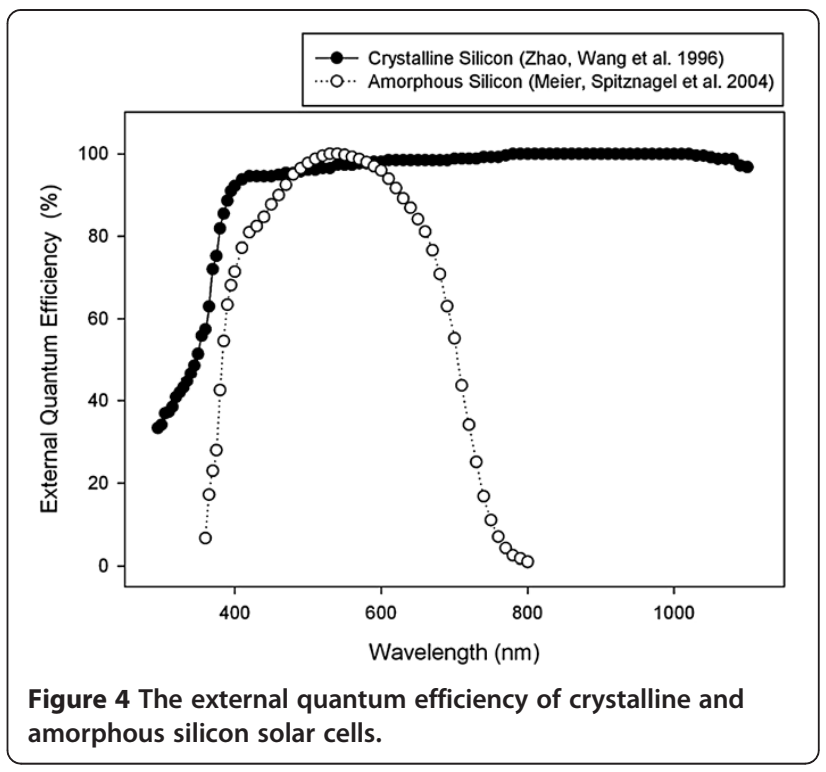

silicon [33] we can calculate the power generated if the light not transmitted by the filters is allowed to fall on the solar cell.

The short circuit current density $\left(\mathrm{J}_{\mathrm{SC}}\right)$ generated by the solar cell is calculated from:

$$
J_{S C}=\int E Q E(\lambda)\left(\frac{\Phi(\lambda)_{A M 1.5}(T(\lambda))}{q}\right)
$$

Where $\operatorname{EQE}(\lambda)$ is the external quantum efficiency as a function of wavelength, $\Phi(\lambda)_{A M 1.5}$ is the photon flux density calculate from the AM1.5 (Global Tilted) solar spectrum, $T(\lambda)$ is the transmittance of the filter as measured from spectroscopy measurements and $q$ is the charge of an electron.

The open circuit voltage $\left(\mathrm{V}_{\mathrm{OC}}\right)$ of the solar cell is also dependent on the short circuit current density and will vary with the irradiance incident upon the cell. This can be calculated from [37]:

$$
V_{O C}=\frac{k T}{q} \ln \left(\frac{J_{S C}+J_{0}}{J_{0}}\right)
$$

Where $E_{g}$ is the band-gap of the semiconductor material, $\mathrm{k}$ is Boltzmann's constant, $\mathrm{T}$ is the cell temperature in $\mathrm{K}$ and $\mathrm{J}_{0}$ is the inferred from the published parameters of each device.

The power generated $(\mathrm{P})$ in $\mathrm{W} \cdot \mathrm{m}^{-2}$ from the cell is then:

$$
P=F F \cdot l_{S C} \cdot V_{O C}
$$

Where the fill factor $(F F)$ is the value published in the literature for each cell type.

The power generated by the solar cell could either be used to run ancillary systems or directed into additional 
lighting. To ensure that the additional lighting is appropriate for the needs of the microalgae Light Emitting Diode (LED) arrays can be used.

The additional PAR power $\left(\mathrm{P}_{\mathrm{PAR}}\right)$ in $\mathrm{Wm}^{-2}$ that can be produced using the power generated $\left(\mathrm{P}_{\text {in }}\right)$ using the system modelled above can be calculated from:

$$
P_{P A R}=E Q E_{L E D} \cdot P_{\text {in }}
$$

Where $\mathrm{EQE}_{\mathrm{LED}}$ is the external quantum efficiency of the LED.

\section{Results}

The spectrum of light passing through three different filters has been modelled as outlined above. The number of carriers generated by each of the solar cell technologies (amorphous silicon and crystalline silicon) when allocated the spectra not transmitted by the blackbox filter are shown in Figure 5.

The power from the spectra transmitted through the various filters and onto the algae is shown below in
Table 1. If no filter was placed on top of the algae, $431 \mathrm{~W} . \mathrm{m}^{-2}$ or $1982 \mu$ mole photons. ${ }^{-1} \cdot \mathrm{m}^{-2}$ would be available for use in the PAR section of the solar spectrum. The calculations from the three filters reflect the fact that smaller portions of the solar spectrum are being transmitted to the algae. Under AM1.5 illumination the highly efficient crystalline silicon cell would produce more electrical power than a less efficient amorphous silicon solar cell. However, from Figure 5 and Table 1 it can be seen that in some cases the amorphous silicon cell will generate more electrical output. This is due to the difference in spectral response between the two technologies. It has been previously shown that amorphous silicon solar cells are more suitable for "blue" spectra while crystalline cells are more suitable for "red" spectra [38]. The higher output using the LEE128 Bright Pink filter can be explained as the filter absorbs a less of the red end of the spectrum than the other filters, which is the region where the amorphous silicon cell has a lower external quantum efficiency than the crystalline silicon device.

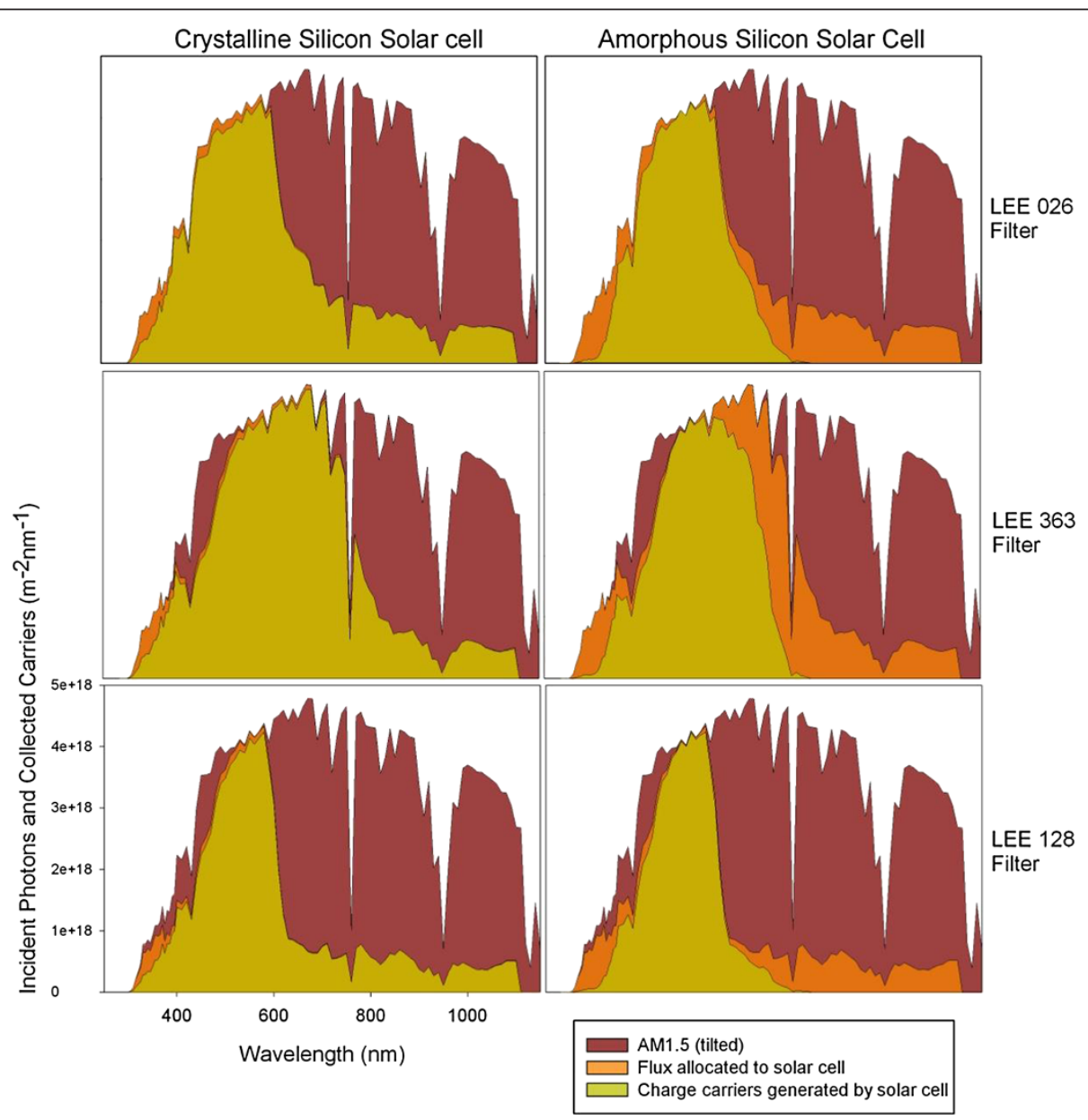

Figure 5 Photon flux and carriers collected for each of the solar cell technologies and filters used. 
Table 1 PAR power transmitted to algae and electrical power generated by solar cells

\begin{tabular}{|c|c|c|c|}
\hline Filter & $\begin{array}{l}\text { PAR power transmitted } \\
\text { to algae }\left(\mathrm{W} \cdot \mathrm{m}^{-2}\right)\end{array}$ & $\begin{array}{l}\text { Power generated by } \\
\text { crystalline silicon }\left(\mathrm{W} \cdot \mathrm{m}^{-2}\right)\end{array}$ & $\begin{array}{l}\text { Power generated by } \\
\text { amorphous silicon }\left(\mathrm{W} . \mathrm{m}^{-2}\right)\end{array}$ \\
\hline None & 431.03 & 0 & 0 \\
\hline LEE 026 Bright red & 71.8 & 121.13 & 81.54 \\
\hline LEE 363 Special medium blue & 47.08 & 151.52 & 93.46 \\
\hline LEE 128 Bright pink & 147.97 & 48.93 & 64 \\
\hline Black (absorbs all light) & 0 & 239.85 & 94.69 \\
\hline
\end{tabular}

As shown in Table 2, if the electricity is used to produce additional light to illuminate the algae the total amount of PAR power can be increased when compared to the PAR transmitted through the filter. The figures shown in Table 2 are from the power generated by a crystalline silicon solar cell as they produce a larger amount of electrical power in most situations. The values for PAR in $\mu$ mole photons. $\mathrm{s}^{-1} \cdot \mathrm{m}^{-2}$ have also been calculated and are shown in Table 3. For the calculation of the additional PAR generated by the LED a wavelength of $650 \mathrm{~nm}$ has been used. This is in the range of what can be absorbed efficiently be algae and can be generated efficiently by LEDs. It should be noted that this value decreases if LEDs are used that emit a shorter wavelength radiation. The value in W. $\mathrm{m}^{-2}$ (Table 2) is independent of the wavelength of the LED and is used in this work to remove the ambiguity associated with wavelength.

\section{Discussion}

There is no doubt that the current fossil fuel resources are depleting. Sustainable alternative energy can replace some of our increasing energy need. One way to meet the need for an alternative, renewable liquid fuel is the production of bioethanol and biodiesel. Microaglae have been suggested as a raw material for bioenergy production. In general, sun light is the main source of all available energy on earth. Light is also the main element for the process of photosynthesis and is the main limiting factor for microalgae growth. Photosynthesis uses approximately $25 \%$ of the solar spectrum (mostly blue and red wavelengths); the rest is either reflected or heats up the growth media. The use of photovoltaics, or solar cells, is a second well established method for converting light into useable energy and has been described as the 'art of converting sunlight directly into electricity' [22]. Whereby, a highly efficient crystalline silicon solar cell can convert up to $24 \%$ of the solar spectrum into electricity [36].

These two methods of energy production would appear to compete for use of the same energy resource (sunlight) to produce either chemical or electrical energy. However, some groups of microalgae (i.e. Chlorophyta) generally only require the blue and red portions of the spectrum whereas solar cells are generally produced with a very broad spectral response to be able to efficiently collect as much of the solar spectrum as possible. Some technologies have a broader response than others as illustrated in Figure 4. By using the AM1.5 direct solar spectrum as a baseline we can model the amount of energy in the incident irradiation that could be converted into electricity by a hypothetical lossless system that diverts part of the solar spectrum to an algae pond and part to a solar cell. For this model we have used readily available lightning filters as proxies for light splitting devices. The spectra the filter transmitted was provided to the algae while the portion absorbed by the filter was allocated to the solar cell.

The addition of a blackbox filter above an algae pond has been modelled and it has been shown in Table 1 that introducing this filter reduces the total amount of PAR power that is incident upon the algae pond. Without this filter in place a PAR power of $431 \mathrm{~W} \cdot \mathrm{m}^{-2}$ is available for algae growth. With the filter in place the available PAR power is reduced to between $47 \mathrm{~W} \cdot \mathrm{m}^{-2}$ and $148 \mathrm{~W} \cdot \mathrm{m}^{-2}$.

Table 2 PAR power transmitted to algae and electrical power generated by crystalline silicon solar cells

\begin{tabular}{|c|c|c|c|c|}
\hline Filter & $\begin{array}{l}\text { PAR power transmitted } \\
\text { to algae }\left(\mathrm{W} \cdot \mathrm{m}^{-2}\right)\end{array}$ & $\begin{array}{l}\text { Power generated by } \\
\text { crystalline silicon (W. } \mathrm{m}^{-2} \text { ) }\end{array}$ & $\begin{array}{l}\text { Additional PAR power } \\
\text { generated by LED }\left(\mathrm{W} \cdot \mathrm{m}^{-2}\right)\end{array}$ & $\begin{array}{l}\text { Total PAR power } \\
\left(\text { W. } \mathrm{m}^{-2}\right)\end{array}$ \\
\hline None & 431.03 & 0 & 0 & 431.03 \\
\hline LEE 026 Bright red & 71.8 & 121.13 & 72.68 & 144.48 \\
\hline LEE 363 Special medium blue & 47.08 & 151.52 & 90.92 & 138 \\
\hline LEE 128 Bright pink & 147.97 & 48.93 & 29.36 & 177 \\
\hline Black (absorbs all light) & 0 & 239.85 & 143.92 & 143.92 \\
\hline
\end{tabular}

The additional PAR power produced by an LED with an EQE of $60 \%$ has also been calculated. The Total PAR Power is the sum of the PAR transmitted to the algae and the PAR generated by the LEDs. 
Table 3 PAR transmitted to algae and electrical power generated by crystalline silicon solar cells

\begin{tabular}{|c|c|c|c|c|}
\hline Filter & $\begin{array}{l}\text { PAR transmitted to algae } \\
\left(\mu \text { mole photons } \mathrm{s}^{-1} \cdot \mathrm{m}^{-2}\right)\end{array}$ & $\begin{array}{l}\text { Power generated by } \\
\text { crystalline silicon }\left(\mathrm{W} \cdot \mathrm{m}^{-2}\right)\end{array}$ & $\begin{array}{l}\text { Additional PAR generated by } \\
\text { LED }\left(\mu \text { mole photons. } \mathrm{s}^{-1} \cdot \mathrm{m}^{-2}\right)\end{array}$ & $\begin{array}{l}\text { Total PAR }(\mu \text { mole } \\
\left.\text { photons. } \mathrm{s}^{-1} \cdot \mathrm{m}^{-2}\right)\end{array}$ \\
\hline None & 1982.13 & 0 & 0 & 1982.13 \\
\hline LEE 026 Bright red & 393.71 & 121.13 & 394.66 & 788.38 \\
\hline LEE 363 Special medium blue & 179.26 & 151.52 & 493.68 & 672.94 \\
\hline LEE 128 Bright pink & 738.34 & 48.93 & 159.43 & 897.78 \\
\hline Black (absorbs all light) & 0 & 239.85 & 781.48 & 781.48 \\
\hline
\end{tabular}

The additional PAR produced by an LED with an EQE of $60 \%$ at $650 \mathrm{~nm}$ has also been calculated.

However, not all PAR is utilised by the algae, as it does not correspond with the absorption peaks of the chlorophylls and pigments as shown in Figure 2. From Figure 2 it can be seen that only a portion of the PAR spectrum is actually absorbed by the chlorophylls and pigments common in microalgae. If an alga such as Chlorella with Chlorophylls $\mathrm{a}$ and $\mathrm{b}$ and $\beta$-carotene, is used it is a reasonable approximation that only $170 \mathrm{~W} \cdot \mathrm{m}^{-2}$ is required for this process, the remainder is not fully utilised. This can be calculated under the assumption that the largest contribution to photosynthesis is from regions where the normalised absorbance is greater than $60 \%$ and the remainder is not critical for growth. For example, the normalised absorption of Chlorella with Chlorophylls a and $b$ and $\beta$-carotene, is greater than $60 \%$ in the regions of $378-485 \mathrm{~nm}$ and $654-670 \mathrm{~nm}$. The amount of solar energy contained in these regions of the AM1.5 spectrum (see Figure 1) is $170 \mathrm{~W} . \mathrm{m}^{-2}$. Thus, a reduction in the amount of PAR may not necessarily effect the growth of the algae, provided the reduction is in the parts of the spectrum the algae do not require for growth or photosynthesis. This is an area that requires further experimental work to determine which parts of the spectrum are needed by the algae and which can be allocated to electricity production.

Based on the model described, using a LEE Special Medium Blue blackbox filter, up to $151 \mathrm{~W} . \mathrm{m}^{-2}$ is generated using a highly efficient crystalline silicon solar cell. This can be allocated to running ancillary systems such as pumps, or directed back into an LED array to provide additional illumination to the algae culture. LEDs have been reported with external quantum efficiencies up to $60 \%$ [28] in the lab. If the power generated by the solar cells is used to generate additional illumination by these LEDs in the parts of the spectrum the algae require for growth the amount of PAR available to the algae can be increased. For the systems modelled above, this increases the total amount of PAR available to the algae up to 177 W.m ${ }^{-2}$. Thus, the total amount of useable PAR incident on an algae pond can be increased by introducing a filter system above an algae pond that directs part of the light to the algae and part to a highly efficient crystalline silicon solar cell and using the generated electricity to produce additional targeted PAR.

The amount of energy production has been calculated for the filter and solar cell combination modelled above that generates the largest amount of total PAR power. These calculations indicate up to $49 \mathrm{Wm}^{-2}$ under AM1.5 (global tilted) radiation or 241 to $482 \mathrm{MJm}^{-2} \mathrm{y}^{-1}$, depending on location in Australia, can be generated by a highly efficient crystalline silicon solar cell which when coupled with an LED array and the light passing through the filter allows $177 \mathrm{~W} \cdot \mathrm{m}^{-2}$ of PAR to illuminate the algae. Assuming a photosynthetic biofuel production rate of a green alga (i.e. Chlorella) with Chlorophylls $a$ and $b$ and $\beta$-carotene $=20 \mathrm{~g} \cdot \mathrm{m}^{-2} \cdot \mathrm{d}^{-1}$ [7], which is equal to around $2-6 \%$ photosynthetic efficiency [39], and a calorific energy content of $15-20 \mathrm{MJkg}^{-1}$, the annual production rate of biofuel will be between 109 and 146 $\mathrm{MJm}^{-2}$ year $^{-1}$. In a light limited system, by increasing the amount of useable PAR, this could be increased. If only $170 \mathrm{~W} \cdot \mathrm{m}^{-2}$ is required for achieving a successful productivity of $20 \mathrm{~g} \cdot \mathrm{m}^{-2} \cdot \mathrm{d}^{-1}$ the increased illumination $\left(177\right.$ W.m $\left.{ }^{-2}\right)$ modelled here could potentially increase the annual algae productivity rate by at least $4 \%$. This may be improved if the selection of microalgae is such that the biofuel production of $20 \mathrm{~g} \cdot \mathrm{m}^{-2} \cdot \mathrm{d}^{-1}$ can be achieved using just the portion of the spectrum absorbed by Chlorophyll $a$.

There are a number of assumptions and limitations in this model. For the total amount of useable PAR with the proposed filter system to be increased relative to the useable PAR without the filter we require a few high efficiency devices. Firstly, the solar cells need to be able to absorb the portions of the spectrum provided to them with very high quantum efficiency and preferably have a broad wavelength response. This would increase the absorption of light in the blue and red portions of the spectrum which are outside of the range of PAR (400 nm - $700 \mathrm{~nm})$. The modelled system also relies on highly efficient LEDs. These can be produced in the lab with external quantum efficiencies ranging up to $60 \%$ [28]. A LED with a higher efficiency will be able to generate larger amounts of useable PAR which would 
improve the growth of the algae. The filter that is used to allocate the solar spectrum to different uses needs to be tailored to the species of algae being cultivated. By doing so, larger portions of the solar spectrum can be directed to the solar cells and thus generating more useable PAR via the LEDs.

We recognise that, if the solar cells are in the order of $25 \%$ efficient, they would be producing more electrical energy per year from the spectrum they receive than the algae are storing as energy. However, the advantage of our proposed method is the production of chemical energy for transportation. We also recognise that the power used to produce extra illumination could be provided by a connection to the electricity grid. However, microalgae are often cultivated in remote areas where an independent power supply may be advantageous. On the other hand, some cultivation systems may have limited amounts of land available for cultivation. In this situation, co-locating the solar array and the algae ponds would result in an increased growth. Additionally there are some other benefits from filtering the light before it is incident upon the algae. The removal of the parts of the spectrum not required by the algae would reduce the heating and evaporation from the algae pond.

\section{Conclusions}

Whilst other factors can influence actual productivity, photosynthesis stipulates the potential upper limit on the effectiveness with which solar energy can be transformed into stored chemical energy (i.e. biofuel). As such, the solar spectrum is the ultimate source of all biomass production. Solar panels have also been recognised as a potential electrical energy production system. By combining two energy production systems we can fully utilize the solar spectrum and light incident on a surface. This would allow both the production of biofuel and electricity from the one facility making efficient use of available land. We propose introducing a filter above the algae pond that will allocate the incident illumination to different purposes. We have modelled this by using commercially available lighting filters as blackbox filters. This hypothetical filter allows the transmitted light through to the algae and used the remainder to generate electricity using either a highly efficient crystalline silicon solar cell or an amorphous silicon solar cell. Using this system up to $151 \mathrm{~W} \cdot \mathrm{m}^{-2}$ of electrical power can be produced. Introducing a method of cogeneration of electrical energy has benefits in the often remote areas microalgae cultivation occurs. This can reduce the costs associated with production, dewatering and extraction of oil from microalgae. This allows for the cheaper and more efficient production of biofuel or value added crops in remote locations which are located away from sources of electrical power. Additionally, we have shown that the total amount of useable PAR incident on an algae pond can be increased by introducing a filter system above an algae pond that directs part of the light to the algae and part to a highly efficient crystalline silicon solar cell and using the generated electricity to produce additional targeted PAR. This can result in a total available PAR of $177 \mathrm{~W} \cdot \mathrm{m}^{-2}$ which can be used to increase the productivity and value of algae cultivation.

\section{Competing interests}

The authors declare that they have no competing interests.

\section{Authors' contributions}

DP and NM jointly developed the model and conceptual framework for the distribution of solar radiation between microalgae and photovoltaics. DP performed numerical modelling and drafted the manuscript. NM contributed specifically in the area of biology and photosynthesis. Both authors read and approved the final manuscript.

\section{Author details}

${ }^{1}$ School of Engineering and Information Technology, Physics and Energy, Murdoch 6150, Western Australia, Australia. ${ }^{2}$ Algae R\&D Centre, School of Veterinary and Life Sciences, Murdoch 6150, WA, Australia. ${ }^{3}$ Murdoch University, Murdoch 6150, WA, Australia.

Received: 20 December 2013 Accepted: 6 June 2014

Published: 11 June 2014

\section{References}

1. Neckel H, Labs D: The solar radiation between 3300 and $12500 \AA$. Sol Phys 1984, 90:205-258.

2. ASTM: Standard Tables for Reference Solar Spectral Irradiances: direct Normal and Hemispherical on $37^{\circ}$ Tilted Surface. In Book Standard Tables for Reference Solar Spectral Irradiances: Direct Normal and Hemispherical on $37^{\circ}$ Tilted Surface, Volume G 173-03. City: ASTM; 2008.

3. Gueymard CA, Myers D, Emery K: Proposed reference irradiance spectra for solar energy systems testing. Sol Energy 2002, 73:443-467.

4. Borowitzka MA: Phycology. In eLS. Volume. John Wiley \& Sons, Ltd; 2012. doi:10.1002/9780470015902.a0000334.pub3.

5. Moheimani NR, Borowitzka MA: Limits to productivity of the alga Pleurochrysis carterae (Haptophyta) grown in outdoor raceway ponds. Biotechnol Bioeng 2006, 96:27-36.

6. Schnitzer I, Yablonovitch E, Caneau C, Gmitter TJ, Scherer A: 30\% external quantum efficiency from surface textured, thin-film light-emitting diodes. Appl Phys Lett 1993, 63:2174-2176.

7. Fon Sing S, Isdepsky A, Borowitzka M, Moheimani N: Production of biofuels from microalgae. Mitig Adapt Strateg Glob Chang 2013, 18:47-72.

8. Moheimani N, Cord-Ruwisch R, Raes E, Borowitzka M: Non-destructive oil extraction from Botryococcus braunii (Chlorophyta). J Appl Phycol 2013, 25:1653-1661.

9. Moheimani NR, Isdepsky A, Lisec J, Raes E, Borowitzka MA: Coccolithophorid algae culture in closed photobioreactors. Biotechnol Bioeng 2011, 9:2078-2087.

10. Moheimani NR: Long term outdoor growth and lipid productivity of Tetraselmis suecica, Dunaliella tertiolecta, and Chlorella sp (Chlorophyta) in bag photobioreactors. J Appl Phycol 2012, doi:10.1007/s10811-012-9850-0.

11. Jeffery SW, Wright SW: Photosynthetic Pigments in the Haptophyta. In Chemical From Microalgae. Edited by Cohen Z. Philadelphia: Taylor and Francis; 1999:111-132.

12. Smith $\mathrm{VH}$ : Light and nutrient dependence of photosynthesis by algae. J Phycol 1983, 19:306-313.

13. Aguirre-Gómez $R$, Weeks AR, Boxall SR: The identification of phytoplankton pigments from absorption spectra. Int J Remote Sens 2001, 22(2\&3):315-338.

14. Agusti S, Enriquez S, Frost-Christensen H, Sand-Jensen K, Duate CM: Light havesting amoung photosynthetic organisms. Funct Ecol 1994, 8:273-279.

15. Boichenko VA: Action spectra and functional antenna sizes of Photosystems I and II in relation to the thylakoid membrane organization and pigment composition. Photosynth Res 1998, 58:163-174. 
16. Corkish R, Green MA, Puzzer T: Solar energy collection by antennas. Sol Energy 2002, 73:395-401.

17. Gardner NF, Muller GO, Shen YC, Chen G, Watanabe S, Gotz W, Krames MR Blue-emitting InGaN-GaN double-heterostructure light-emitting diodes reaching maximum quantum efficiency above $200 \mathrm{~A} / \mathrm{cm}$ [sup 2]. Appl Phys Lett 2007, 91:243506.

18. Zhu X-G, Long SP, Ort DR: What is the maximum efficiency with which photosynthesis can convert solar energy into biomass? Curr Opin Biotechnol 2008, 19:153-159.

19. Moheimani $\mathrm{N}$, Borowitzka $\mathrm{M}$ : Increased $\mathrm{CO}_{2}$; and the effect of $\mathrm{pH}$ on growth and calcification of Pleurochrysis carterae and Emiliania huxleyi (Haptophyta) in semicontinuous cultures. Appl Microbiol Biotechnol 2011, 90:1399-1407.

20. Frigaard N-U, Larsen KL, Cox RP: Spectrochromatography of photosynthetic pigments as a fingerprinting technique for microbial phototrophs. FEMS Microbiol Ecol 1996, 20:69-77.

21. Moheimani NR, Parlevliet D: Sustainable solar energy conversion to chemical and electrical energy. Renew Sust Energ Rev 2013, 27:494-504.

22. Wenham SR, Green MA, Watt ME: Applied Photovoltaics. Centre for Photovoltaic Devices and Systems: Sydney; 1994.

23. Chapin DM, Fuller CS, Pearson GL: A new silicon $p-n$ junction photocell for converting solar radiation into electrical power. J Appl Phys 1954, 25:676-677.

24. Green MA, Emery K, Hishikawa Y, Warta W, Dunlop ED: Solar cell efficiency tables (version 39). Prog Photovolt Res Appl 2012, 20:12-20

25. Beardall J, Stojkovic S, Larsen S: Living in a high $\mathrm{CO}_{2}$ world: impacts of global climate change on marine phytoplankton. Plant Ecol Divers 2009, 2:191-205.

26. Singh $D$, Jennings $P$ : The Outlook for Crystalline Solar Photovoltaic Technology over the Next Decade. AIP Conference Proceedings 2007, 941:98-110.

27. Kim S-Y, Jeong W-I, Mayr C, Park Y-S, Kim K-H, Lee J-H, Moon C-K, Brütting W, Kim J-J: Organic Light-Emitting Diodes with 30\% External Quantum Efficiency Based on a Horizontally Oriented Emitter. Adv Funct Materials 2013, 23:3896-3900.

28. Krames MR, Ochiai-Holcomb M, Hofler GE, Carter-Coman C, Chen El, Tan I-H, Grillot P, Gardner NF, Chui HC, Huang J-W, Stockman SA, Fish FA, Craford MG, Tan TS, Kocot CP, Hueschen M, Posselt J, Loh B, Sasser G, Collins D: High-power truncated-inverted-pyramid $\left(\mathrm{Al}_{\mathrm{x}} \mathrm{Ga}_{1-\mathrm{x}}\right)_{0.5} \mathrm{In}_{0.5} \mathrm{P} / \mathrm{GaP}$ light-emitting diodes exhibiting $>50 \%$ external quantum efficiency. Appl Phys Lett 1999, 75:2365-2367.

29. Rosenberg V, Vasiliev M, Alameh K: A Spectrally Selective Panel. In Book A Spectrally Selective Panel. City: WO Patent; 2013. 2,013,003,890.

30. Sark WGJHM, Barnham KWJ, Slooff LH, Chatten AJ, Büchtemann A, Meyer A, McCormack SJ, Koole R, Farrell DJ, Bose R, Bende EE, Burgers AR, Budel T, Quilitz J, Kennedy M, Meyer T, Donegá CD, Meijerink A, Vanmaekelbergh D: Luminescent Solar Concentrators - a review of recent results. Opt Express 2008, 16:21773-21792.

31. Cuevas A, Sinton RA, Kerr M, Macdonald D, Mackel H: A contactless photoconductance technique to evaluate the quantum efficiency of solar cell emitters. Sol Energy Mater Sol Cells 2002, 71:295-312.

32. Meier J, Spitznagel J, Kroll U, Bucher C, Fay S, Moriarty T, Shah A: Potential of Amorphous and Microcrystalline Silicon Solar Cells. In Thin Solid Films Symposium D on Thin Film and Nano-Structured Materials for Photovoltaics, proceedings of the E-MRS 2003 Spring Conference, 10-13 June 2003; 2004:451-452. 518-524.

33. Meier J, Spitznagel J, Kroll U, Bucher C, FaÃ i S, Moriarty T, Shah A: Potential of amorphous and microcrystalline silicon solar cells. Thin Solid Films 2004, 451-452:518-524.

34. Kupich M, Grunsky D, Kumar P, Schroder B: Preparation of microcrystalline single junction and amorphous-microcrystalline tandem silicon solar cells entirely by hot-wire CVD. Sol Energy Mater Sol Cells 2004, 81:141-146.

35. Droz C, Vallat-Sauvain E, Bailat J, Feitknecht L, Meier J, Niquille X, Shah A: Electrical and microstructural characterisation of microcrystalline silicon layers and solar cells. In Photovoltaic Energy Conversion, 2003 Proceedings of 3rd World Conference on; 18-18 May 2003; 2003:1544-1547. Vol.1542.

36. Zhao J, Wang A, Altermatt PP, Wenham SR, Green MA: 24\% efficient perl silicon solar cell: recent improvements in high efficiency silicon cell research. Sol Energy Mater Sol Cells 1996, 41-42:87-99.
37. Messenger RA, Ventre J: Photovoltaic Systems Engineering. 3rd edition. Boca Raton, FL: CRC Press; 2010.

38. Ruther R, Kleiss $G$, Reiche $K$ : Spectral effects on amorphous silicon solar module fill factors. Sol Energy Mater Sol Cells 2002, 71:375-385.

39. Ritchie RJ: Modelling photosynthetic photon flux density and maximum potential gross photosynthesis. Photosynthetica 2010, 48:596-609.

doi:10.1186/2046-9063-10-4

Cite this article as: Parlevliet and Moheimani: Efficient conversion of solar energy to biomass and electricity. Aquatic Biosystems 2014 10:4.

\section{Submit your next manuscript to BioMed Central and take full advantage of:}

- Convenient online submission

- Thorough peer review

- No space constraints or color figure charges

- Immediate publication on acceptance

- Inclusion in PubMed, CAS, Scopus and Google Scholar

- Research which is freely available for redistribution 